\title{
Higher Doses of (+)MK-801 (Dizocilpine) Induced Mortality and Procedural but Not Cognitive Deficits in Delayed Testing in the Active Place Avoidance With Reversal on the Carousel
}

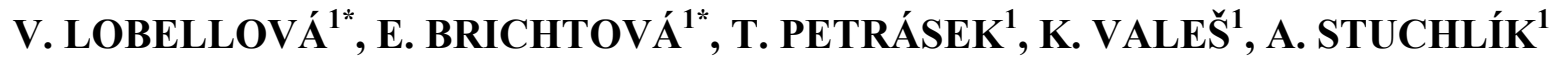 \\ * These authors contributed equally to this study.
}

${ }^{1}$ Institute of Physiology, Czech Academy of Sciences, Prague, Czech Republic

Received May 22, 2014

Accepted August 29, 2014

On-line October 15, 2014

\begin{abstract}
Summary
Schizophrenia is a devastating disorder affecting $1 \%$ of the world's population. An important role in the study of this disease is played by animal models. Since there is evidence that acute psychotic episodes can have consequences on later cognitive functioning, the present study has investigated the effects of a single systemic application of higher doses of (+)MK-801 ( $3 \mathrm{mg} / \mathrm{kg}$ and $5 \mathrm{mg} / \mathrm{kg}$ ) to adult male Long-Evans rats from the Institute's breeding colony on delayed testing in the active place avoidance task with reversal on the Carousel (a rotating arena). Besides significant mortality due to the injections, a disruption of procedural functions in active place avoidance, after the dose $5 \mathrm{mg} / \mathrm{kg}$ was observed. It was concluded that Long-Evans rats from our breeding colony do not represent a suitable biomodel for studying the effects of single high-dose NMDA antagonists.
\end{abstract}

\section{Key words}

Dizocilpine • (+)MK-801 • Active place avoidance • Carousel • Long-Evans rats

\section{Corresponding author}

A. Stuchlík, Institute of Physiology CAS, Videnska 1083, 14220 Prague 4, Czech Republic. Fax: +420 24106 2488. E-mail: stuchlik@biomed.cas.cz

Schizophrenia is a devastating neuropsychiatric disorder, affecting approx. $1 \%$ of the population worldwide (van Os and Kapur 2009). Its symptoms may be roughly divided into positive (hallucinations, delusions), negative (social flattening, anhedonia) and cognitive deficits (van Os and Kapur 2009). Although cognitive deficits in schizophrenic patients were previously regarded as secondary (and also as consequence of classical antipsychotic medication), today they are viewed as primarily the most stable symptoms of the disorder, often present in remission and also in some first-degree relatives, forming an endophenotype of the disease (Elvevåg and Goldberg 2000). Researchers have successfully employed animal models to study mechanisms, outcomes and potential therapy for this disorder (for review see Jones et al. 2011).

Recently collected evidence from both preclinical and clinical studies suggest that even a first schizophrenic attack may have serious consequences on later cognitive functioning. Clinical evidence using virtual reality testing in schizophrenic patients revealed a cognitive deficit in first-episode schizophrenic patients, compensated with atypical antipsychotic medication (Fajnerová et al. 2014). Moreover, recent studies using rodents as preclinical models (Wiescholleck and Manahan-Vaughan 2013a,b) have demonstrated a significant impairment of long-term potentiation, changes in NMDA receptor sub-units and corrupted learning after a systemic administration of (+)MK-801 at high doses.

To further investigate the consequences of psychotic episodes on late place memory, cognitive coordination and flexibility (Hatalova et al. 2014) and spatial representation, we have designed a study in which $(+)$ MK-801 was applied at doses $3 \mathrm{mg} / \mathrm{kg}$ and $5 \mathrm{mg} / \mathrm{kg}$ in a single injection and delayed testing in active place 
avoidance with reversal on a Carousel (commencing 10 days after application) demanding cognitive coordination and flexibility (Wesierska et al. 2005). We hypothesized that navigation in active place avoidance will be affected by the injection. Male adult Long-Evans rats were obtained from the breeding colony of Institute of Physiology, of the Czech Academy of Sciences. All animals weighed 300-400 $\mathrm{g}$ at the start of experiment and were 12-15 weeks of age. No systematic differences between groups in the age were present to avoid batch effects. Animals were housed in groups of three to four per cage, in an air-conditioned accredited animal room with a stable temperature of $22{ }^{\circ} \mathrm{C}$, constant humidity and 12/12 light/dark regime with lights on at 7:00. All experiments were conducted in the light phase of the day. Food and water was provided ad libitum. Prior to the experiments animals were handled by experimenters for 2 min each day for 3 days. Before experiments in the active place avoidance task, animals were also gently implanted with a subcutaneous needle connector, which pierced the skin between rat's shoulders. The needle had a blunted and swirled end for the attachment of an alligator clip connecting a shock-delivering wire. This procedure is analogous to hypodermic injection in humans and does not require anesthesia. All animal manipulations were conducted in accordance with the Animal Protection Code of the Czech Republic and corresponding directives of the European Community Council (2010/63/EC).

$(+) M K-801$ (dizocilpine hydrogen maleate; obtained from SigmaAldrich, CR) was dissolved in sterile saline at concentrations of 3 and $5 \mathrm{mg} / \mathrm{ml}$. Fresh solutions were prepared on the day of injection and stored in a refrigerator between injections.

The experiment involved 31 rats. Control group $(n=11)$ obtained intraperitoneally saline at the day of injection, the group treated with $3 \mathrm{mg} / \mathrm{kg}(\mathrm{n}=7)$ obtained $3 \mathrm{mg} / \mathrm{kg}$ of $(+) \mathrm{MK}-801$ dissolved in sterile saline and the group with $5 \mathrm{mg} / \mathrm{kg}(\mathrm{n}=13)$ obtained also $(+) \mathrm{MK}-801$ at the mentioned dose on the day of injection. Animals were tested after 10 days in active place avoidance with a Carousel. A longer interval compared to previous studies was selected, since we aimed at investigating longer-term consequences of the acute psychotic episode and also because we desired the animal fully recover, as there was significant acute mortality, especially in the group injected with $5 \mathrm{mg} / \mathrm{kg}$ of (+)MK-801 (see later). There were four acquisition sessions with the sector arbitrarily defined at the North, followed by four reversal session during which the to-be avoided sector (see next section) was relocated 180 degrees to the South.

The apparatus has been described previously in detail (Wesierska et al. 2005, Stuchlik et al. 2007, 2013). Briefly, it consists of a smooth metal disk $(82 \mathrm{~cm}$ in diameter; elevated $1 \mathrm{~m}$ above the room floor), which rotates clockwise at 1 revolution per minute (rpm). A 50cm-high transparent wall made of clear Plexiglas surrounds the arena. The animals had to avoid an unmarked, 60-deg to-be-avoided sector identified solely by its relationships to distal room cues. The position of the shock sector remained stable throughout each phase. The only change of the sector position occurred before the reversal phase.

The rats wore a rubber harness, which carried an infrared LED between animal's shoulders. A computerbased tracking system (iTrack; Tracker, Biosignal Group, USA) located in an adjacent room recorded the rat's position at a frequency of $25 \mathrm{~Hz}$. Position series were stored for off-line analysis (TrackAnalysis; Biosignal Group, USA). Whenever the rat entered the to-be-avoided sector for more than $300 \mathrm{~ms}$, the tracking system delivered a mild electric shock $(50 \mathrm{~Hz}, 0.5 \mathrm{~s}, 0.4-0.6 \mathrm{~mA})$ and counted an entrance. If the rat did not leave the sector, additional shocks were given every $900 \mathrm{~ms}$, but no more entrances were counted until the rat left the sector for more than $300 \mathrm{~ms}$. Shocks were delivered through the implanted needle and the grounded arena floor (the highest voltage drop and perception of shocks were between rats' paws and floor). This shocking procedure was previously shown to be effective and safe for rats, leading to rapid avoidance behavior (Wesierska et al. 2005, Stuchlik et al. 2007). The current was individualized for each rat to elicit a rapid escape response but to prevent freezing. In most cases, animals responded appropriately to $0.4 \mathrm{~mA}$. There were no systematic differences between shock intensities between strains. After each rat, the floor was cleaned with detergent, ensuring the rats could not use inter-trial scent marks.

We selected the following measures for statistical analysis: Total distance measured in the arena frame, reflecting only passive locomotion had normal distribution and did not have to be transformed. Number of errors (entrances into the sector) had skewed distribution and were normalized by logarithmic transformations as well as data from a skill learning index, which indicates the efficiency of escape reaction and is a measure of procedural learning and cognitive skill (Dockery and Wesierska 2010, Wesierska et al. 
2013). The skill learning index was calculated by dividing the total number of shocks by the number of entrances. One rat from the control, intact group was excluded from analysis, as it had not fewer than 19 errors in all sessions (in one session, number of error reached even 133). Data from active place avoidance were evaluated by separate two-way repeated-measure ANOVAs for acquisition and reversal, where groups served as a between subject factor and sessions served as repeated measure. Post-hoc analysis between groups and sessions were computed with a Tukey's post-hoc test; however, only differences between groups are reported in figures. All differences between daily sessions are reported in the main text.

After injection of both doses of (+)MK-801, acute psychosis was detected by visual observation in the open-field arena (data not reported); animals exhibited signs of strong hyperlocomotion, stereotypies and intermittent episodes of ataxia. No such changes were observed in control group that obtained saline. However, in the groups treated with $5 \mathrm{mg} / \mathrm{kg}$ we observed significant mortality; 7 out of 13 animals in this group died during the following week after injection. In the group treated with $3 \mathrm{mg} / \mathrm{kg}$ only 2 animals out of $7 \mathrm{died}$. Due to technical limitations, we did not pursue autopsies, so we could not determine the reasons for these deaths. No animal from control groups has died. To sum up, only 5 rats treated with $3 \mathrm{mg} / \mathrm{kg}$ of (+)MK-801 and 6 rats with the dose $5 \mathrm{mg} / \mathrm{kg}$ entered the behavioral study.

When tested in active place avoidance on a Carousel, animals showed differences in locomotor activity (Fig. 1AB). A two-way ANOVA computed on acquisition sessions for distance traveled revealed a significant main effect of groups $(\mathrm{F}(2,19)=5.084$, $\mathrm{P}=0.017)$ but only a trend for main effect of sessions $(\mathrm{F}(3,57)=2.384, \quad \mathrm{P}=0.079)$. However, an interaction between these two factors was found $(\mathrm{F}(6,57)=2.447$, $\mathrm{P}=0.036$ ). A post-hoc test of main factor of groups showed that only the group applied with $5 \mathrm{mg}$ showed a decrease in traveled distance $(\mathrm{P}=0.02)$ in all sessions except the first acquisition sessions $\left(\mathrm{Ps}_{\mathrm{S}}<0.005\right)$. No difference was seen after the $3 \mathrm{mg}$ of $(+) \mathrm{MK}-801$ $(\mathrm{P}>0.05)$. Distance traveled in reversal sessions was affected by $(+)$ MK-801 treatment. Main effect of groups was again found to be significant $(\mathrm{F}(2,19)=5.084$, $\mathrm{P}=0.017)$. The main effect of neither sessions $(\mathrm{F}(3,57)=2.103, \mathrm{P}=0.11)$ nor interaction $(\mathrm{F}(6,57)=2.103$, $\mathrm{P}=0.68)$ was confirmed by the two-way ANOVA. Tukey's post-hoc test revealed that only the group treated with $5 \mathrm{mg}$ of $(+) \mathrm{MK}-801$ showed significantly lower locomotion $(\mathrm{P}=0.007)$. The effect of the $3 \mathrm{mg} / \mathrm{kg}$ treatment did not differ from control group $(\mathrm{P}=0.96)$. This suggests locomotor impairment of rats treated with $(+)$ MK-801 at the dose $5 \mathrm{mg} / \mathrm{kg}$, even after 7-day latency.

Results from number of errors are illustrated in Figure $1 C D$. When evaluating the number of entrances, differences between sessions were found. Number of entrances in acquisition sessions was affected by main effect of sessions $(F(3,57)=13.61, P=0.000)$. Neither effect of groups $(\mathrm{F}(2,19)=2.3, \mathrm{P}=0.128)$ nor interaction $(\mathrm{F}(6,57)=0.39, \quad \mathrm{P}=0.88)$ was shown. More detailed analysis of main effect of sessions showed significant impairment on sessions 3 and $4(\mathrm{Ps}<0.0005)$. Control group and the group treated with $3 \mathrm{mg}$ of $(+) \mathrm{MK}-801$ significantly improved in session $4 \quad\left(\mathrm{Ps}_{\mathrm{s}}<0.008\right.$, $\mathrm{NK}<0.011$ ). In reversal, only a main effect of sessions was detected to be significant $(\mathrm{F}(3,57)=3.351, \mathrm{P}=0.025)$. A Two-way ANOVA did not show significant main effect of groups $(\mathrm{F}(2,19)=1.306, \mathrm{P}=0.294)$ or interaction $(\mathrm{F}(6,57)=0.828, \mathrm{P}=0.554)$. Post-hoc analysis of the main factor of sessions showed an improvement in sessions 2 and 4 (Ps $<0.022)$. However, only control group improved significantly in session $2(\mathrm{P}=0.0051)$.

When analyzing the skill learning index as a measure of escape reaction, significant differences were found (Fig. 1EF). In acquisition sessions, a main effect of groups was shown $(\mathrm{F}(2,19)=5.385, \mathrm{P}=0.024)$, but no main effect of sessions $(F(3,57)=1.538, p=0.215)$ nor interaction between these two factors $(\mathrm{F}(6,57)=1.933$, $\mathrm{P}=0.091$ ). A post-hoc test computed on the group factor showed a significant effect of the $5 \mathrm{mg} / \mathrm{kg}$ dose $(\mathrm{P}=0.017)$. Control group improved over sessions (skill learning index decreased), while the $3 \mathrm{mg} / \mathrm{kg}$ group fluctuated. However none of this was confirmed by the post-hoc test. Analysis of reversal sessions by a two-way ANOVA showed a significant main effect of groups $(\mathrm{F}(2,19)=6.333), \mathrm{P}=0.008)$, but failed to show effect of sessions $(\mathrm{F}(3,57)=0.689, \quad \mathrm{P}=0.562)$ and interaction between these two $(\mathrm{F}(6,57)=1.001, \mathrm{P}=0.433)$. A post - hoc test revealed significant effect of $5 \mathrm{mg}$ dose $(\mathrm{P}=0.018)$. This again suggests procedural impairment and disruption of skill and escape learning in animals treated with $5 \mathrm{mg} / \mathrm{kg}(+) \mathrm{MK}-801$.

To determine whether rats were able to initially understand the task we analyzed their performance on day 1 of acquisition and reversal session in two $10 \mathrm{~min}$ blocks. Distance traveled (Fig. 2AB) on day 1 of acquisition session decreased throughout the session, but 

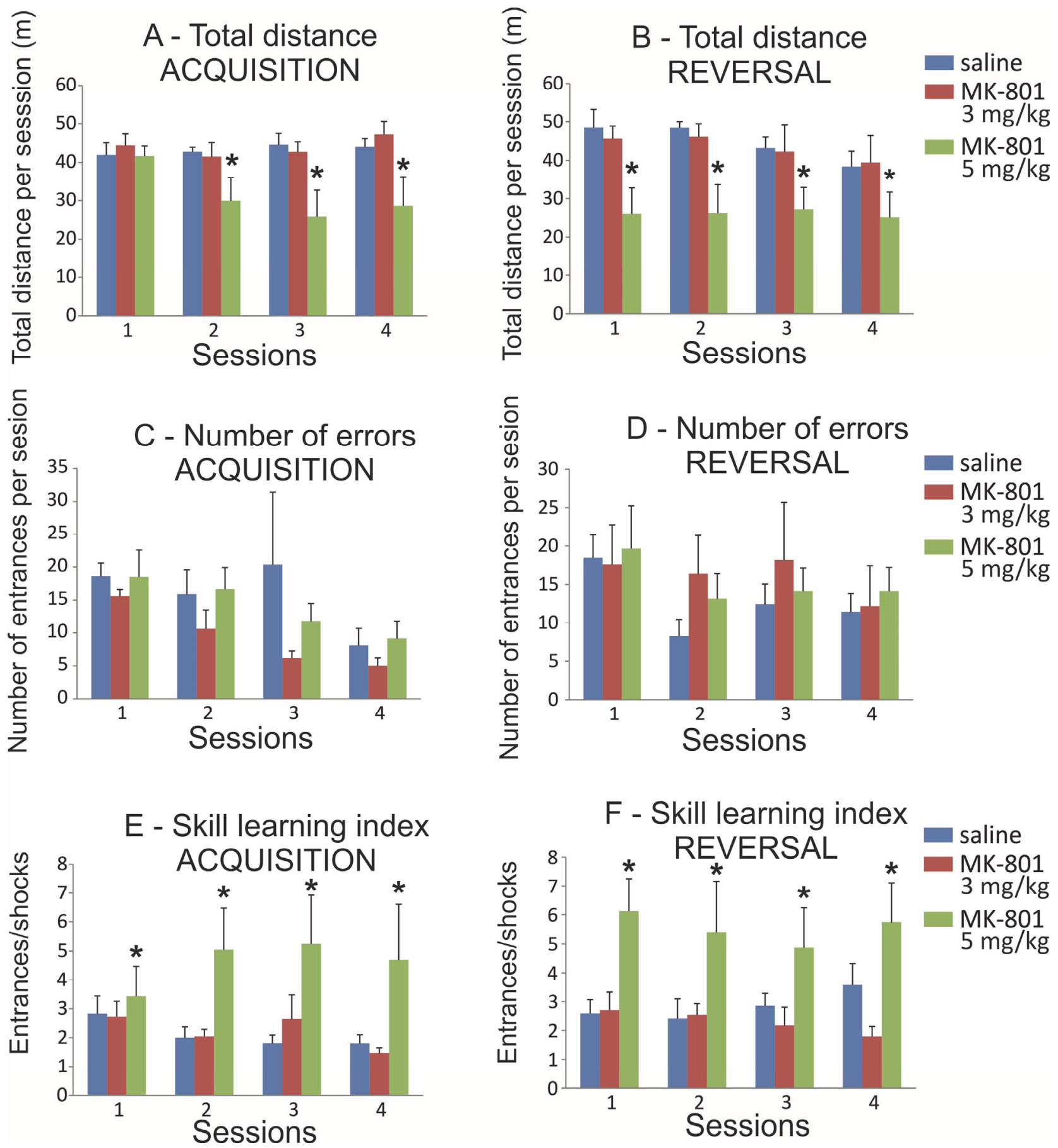

Fig. 1. Panel A: This graph illustrates total distance traveled per each acquisition session and shows a differences between groups, where only a group treated with (+)MK-801 at $5 \mathrm{mg} / \mathrm{kg}$ showed and impairment except the first session (see Results for interaction report). Application of (+)MK-801 at $3 \mathrm{mg} / \mathrm{kg}$ was without effect. Panel B shows decrease in the total distance in reversal sessions, when, again, only application of (+)MK-801 at the dose $5 \mathrm{mg} / \mathrm{kg}$ had a significant effect. Panels $\mathbf{C}$ and $\mathbf{D}$ show effects of two doses of (+)MK-801 on total number of errors in acquisition and reversal sessions, respectively. No differences between groups were detected, for differences between session, see Results section. Panels E and F show skill learning index in acquisition and reversal sessions, respectively (shocks/entrances ratio; please note in Methods that shock were repeated until the rat did not leave the sector). Again, significant worsening of skill learning index was detected only after application of higher dose of $(+) \mathrm{MK}-801(5 \mathrm{mg} / \mathrm{kg}) . * \mathrm{P}<0.05$

two-way ANOVA only confirmed significant effect of 10 min blocks $(\mathrm{F}(1,19)=18.81, \mathrm{P}=0.00)$ and interaction $(\mathrm{F}(2,19)=5.09, \mathrm{P}=0.17)$, main effect of groups was not observed $(\mathrm{F}(2,19)=0.16, \mathrm{P}=0.85)$. In reversal session, locomotor activity also decreased and was affected by main effect of groups $(\mathrm{F}(2,19)=3.969, \mathrm{P}=0.037)$ and main effect of blocks $(\mathrm{F}(1,19)=9.876, \mathrm{P}=0.006)$, no interaction $\quad(\mathrm{F}(2, \quad 19)=0.97, \quad \mathrm{P}=0.398)$ was found. 

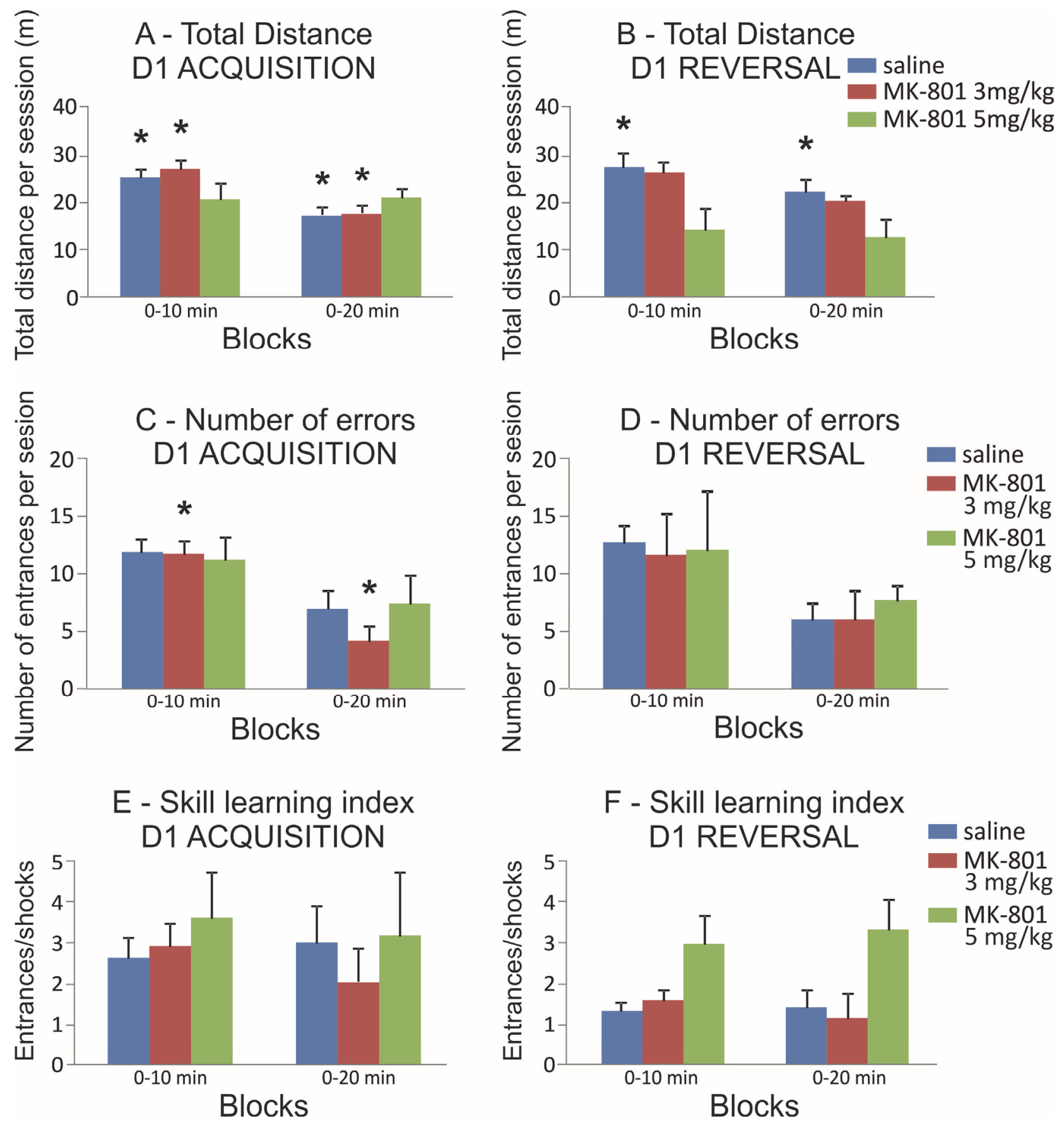

Fig. 2. Panels $\mathbf{A}$ and $\mathbf{B}$ show decrease in locomotor activity on day 1 of acquisition and reversal session. Control group showed significant decrease throughout the session in both acquisition and reversal. Only group treated with (+)MK-801 at $3 \mathrm{mg} / \mathrm{kg}$ significantly lowered traveled distance in acquisition session but not in reversal session. Group applied with $5 \mathrm{mg} / \mathrm{kg}$ of (+)MK-801 did not show any difference over 10 min blocks. Number of errors on day 1 of acquisition session shown in panel $\mathbf{C}$ was significantly affected only by application of $3 \mathrm{mg} / \mathrm{kg}$ of (+)MK-801. Control group and group treated with $5 \mathrm{mg} / \mathrm{kg}$ of $(+) \mathrm{MK}-801$ showed decrease in number of errors during one session though this effect was not proved as significant. Panel D shows effect of (+)MK-801 on number of errors in the first acquisition and reversal session. No effect of applied drug was observed. Panels $\mathbf{E}$ and $\mathbf{F}$ illustrate changes in skill learning index. Again no significant effect of (+)MK-801 was observed over blocks of the first acquisition and reversal session. * P<0.05

In the first acquisition session number of errors (Fig. 2CD) decreased and was only affected by blocks factor $(F(1,19)=20.17, P=0.000)$, no significant effect of groups factor $(\mathrm{F}(2,19)=0.3, \mathrm{P}=0.745)$ nor interaction $(F(2,19)=0.73, P=0.496)$ was found. In reversal session, two-way ANOVA again confirmed significant main effect of blocks $(\mathrm{F}(1,19)=8.969, \mathrm{P}=0.007)$, but failed to show effect of groups $(\mathrm{F}(2,19)=0.038, \mathrm{P}=0.963)$ and interaction $(\mathrm{F}(2,19)=0.155, \mathrm{P}=0.857)$ between these two factors. 
Two-way ANOVA computed on skill learning index (Fig. 2EF) in acquisition session revealed only trend in main effect of blocks factor $(F(1,19)=3.625$, $\mathrm{P}=0.072)$ but no effect of groups $(\mathrm{F}(2,19)=0.118$, $\mathrm{P}=0.889)$ nor interaction $(\mathrm{F}(2,19)=1.169, \mathrm{P}=0.332)$ was observed. Skill learning index in the first reversal session showed only slight trend in groups effect $(F(2,19)=2.87$, $\mathrm{P}=0.081$ ) and again failed to show interaction $(\mathrm{F}(2,19)=0.128, \quad \mathrm{P}=0.88) \quad$ and effect of blocks $(\mathrm{F}(1,19)=2.278, \mathrm{P}=0.148)$.

The present results show that the application of $5 \mathrm{mg} / \mathrm{kg}$, but not $3 \mathrm{mg} / \mathrm{kg}$ of (+)MK-801 seriously affects behavior in the active place avoidance on a Carousel. The deficit was not, however, cognitive in nature; instead, it was manifested by decreased locomotion and impaired skill to escape from the to-be-avoided sector upon the first entrance and shock. Additionally, we observed approximately a $53 \%$ mortality in the group treated with the higher dose and more than a $20 \%$ mortality after application of lower dose. This suggests a preferential sensitivity of animals from our breeding colony to higher doses of $(+) \mathrm{MK}-801$. This data strongly contradicts previous findings (Wiescholleck and Manahan-Vaughan 2012, 2013a,b), who did not observe mortality and reported significant cognitive deficit in impairment of object-recognition memory at various intervals after application of even high doses $(10 \mathrm{mg} / \mathrm{kg})$ to young Wistar rats. Moreover earlier studies suggest persisting cognitive deficits after the application of high doses (Lukoyanov and Paula-Barbosa 2000, Wozniak et al. 1996). However, such doses were probably capable of eliciting Olney's lesions (Olney et al. 1991). With the present data, we cannot explain difference between the study and previous studies, but differences in age, strains, breeding, testing intervals and other factors must be taken into account.

The present study has a few limitations. First is the relatively low number of animal that survived after MK-801 injections and thus entered the behavioral testing. Finally, the data may be viewed as a bit preliminary due to the fact that only Long-Evans strain from our breeding colony were included with no interstrain comparison. It is known that these issues have effects of performance in a multitude of cognitive tasks (Jakubowska-Dogru et al. 2003, Andrews 1996).

To conclude, the results indicate that our LongEvans rats are not a suitable model for the effects of induction of a strong psychotic episode with high dose of the psychotomimetic on latter behavior. This conclusion is also supported by unpublished pilot data, when we subjected those rats who had survived in the study to testing at the 6-day incremental (reference memory) version of the Morris water maze with a 30-day latency from application and detected absolutely no deficit. We currently pursue experiments involving subchronic and chronic application of lower doses of $(+) \mathrm{MK}-801$ (ranging from 0.05 to $0.5 \mathrm{mg} / \mathrm{kg}$ ) to postnatal (PD7-11), adolescent and adult rats (Beninger et al. 2002, Li et al. 2011).

\section{Conflict of Interest}

There is no conflict of interest.

\section{Acknowledgements}

This study was supported by IGA MZ CR grant NT13386. Institutional support was provided by RVO:67985823. We thank all members of the laboratory and students for their valuable support. We are also grateful to P. M. Luketic for language revision.

\section{References}

ANDREWS JS: Possible confounding influence of strain, age and gender on cognitive performance in rats. Cogn Brain Res 3: 251-267, 1996.

BENINGER RJ, JHAMANDAS A, AUJLA H, XUE L, DAGNONE RV, BOEGMAN RJ, JHAMANDAS K: Neonatal exposure to the glutamate receptor antagonist (+)MK-801: effects on locomotor activity and pre-pulse inhibition before and after sexual maturity in rats. Neurotox Res 4: 477-488, 2002.

DOCKERY CA, WESIERSKA MJ: A spatial paradigm, the allothetic place avoidance alternation task, for testing visuospatial working memory and skill learning in rats. J Neurosci Methods 191: 215-221, 2010.

ELVEVÅG B, GOLDBERG TE: Cognitive impairment in schizophrenia is the core of the disorder. Crit Rev Neurobiol 14: $1-21,2000$. 
FAJNEROVÁ I, RODRIGUEZ M, LEVČÍK D, KONRÁDOVÁ L, MIKOLÁŠ P, BROM C, STUCHLÍK A, VLČEK K, HORÁČEK J: A virtual reality task based on animal research - spatial learning and memory in patients after the first episode of schizophrenia. Front Behav Neurosci 8:157, 2014.

HATALOVA H, RADOSTOVA D, PISTIKOVA A, VALES K, STUCHLIK A: Spatial reversal learning in chronically sensitized rats and in undrugged sensitized rats with dopamine $\mathrm{D}_{2}$-like receptor agonist quinpirole. Front Behav Neurosci 8:122, 2014.

JAKUBOWSKA-DOGRU E, GUMUSBAS U, KARA F: Individual variation in the spatial reference and working memory assessed under allothetic and idiothetic orientation cues in rat. Acta Neurobiol Exp (Wars) 63: 17-23, 2003.

JONES CA, WATSON DJG, FONE K: Animal models of schizophrenia. Br J Pharmacol 164: 1162-1194, 2011.

LI JT, SU YA, GUO CM, FENG Y, YANG Y, HUANG RM, SI TM: Persisting cognitive deficits induced by low-dose, subchronic treatment with (+)MK-801 in adolescent rats. Eur J Pharmacol 652: 65-72, 2011.

LUKOYANOV NV, PAULA-BARBOSA MM: A single high dose of dizocilpine produces long-lasting impairment of the water maze performance in adult rats. Neurosci Lett 285: 139-142, 2000.

OLNEY JW, LABRUYERE J, WANG G, WOZNIAK DF, PRICE MT, SESMA MA: NMDA antagonist neurotoxicity: mechanism and prevention. Science 254: 1515-1518, 1999.

STUCHLIK A, REHAKOVA L, RAMBOUSEK L, SVOBODA J, VALES K. Manipulation of D2 receptors with quinpirole and sulpiride affects locomotor activity before spatial behavior of rats in an active place avoidance task. Neurosci Res 58: 133-139, 2007.

STUCHLÍK A, PETRÁSEK T, PROKOPOVÁ I, HOLUBOVÁ K, HATALOVÁ H, VALEŠ K, KUBÍK S, DOCKERY C, WESIERSKA M: Place avoidance tasks as tools in the behavioral neuroscience of learning and memory. Physiol Res.62 (Suppl 1): S1-S19, 2013.

VAN OS J, KAPUR S: Schizophrenia. Lancet 374: 635-645, 2009.

WESIERSKA M, DOCKERY C, FENTON AA: Beyond memory, navigation, and inhibition: behavioral evidence for hippocampus-dependent cognitive coordination in the rat. J Neurosci 25: 2413-2419, 2005.

WESIERSKA MJ, DUDA W, DOCKERY CA: Low-dose memantine-induced working memory improvement in the allothetic place avoidance alternation task (APAAT) in young adult male rats. Front Behav Neurosci 7:203, 2013.

WIESCHOLLECK V, MANAHAN-VAUGHAN D: PDE4 inhibition enhances hippocampal synaptic plasticity in vivo and rescues MK801-induced impairment of long-term potentiation and object recognition memory in an animal model of psychosis. Transl Psychiatry 2:e89, 2012.

WIESCHOLLECK V, MANAHAN-VAUGHAN D: Long-lasting changes in hippocampal synaptic plasticity and cognition in an animal model of NMDA receptor dysfunction in psychosis. Neuropharmacology 74: 48-58, 2013a.

WIESCHOLLECK V, MANAHAN-VAUGHAN D: Persistent deficits in hippocampal synaptic plasticity accompany losses of hippocampus-dependent memory in a rodent model of psychosis. Front Integr Neurosci 7:12, 2013b.

WOZNIAK DF, BROSNAN-WATTERS G, NARDI A, MCEWEN M, CORSO TD, OLNEY JW, FIX AS: MK-801 neurotoxicity in male mice: histologic effects and chronic impairment in spatial learning. Brain Res 707: 165179, 1996. 